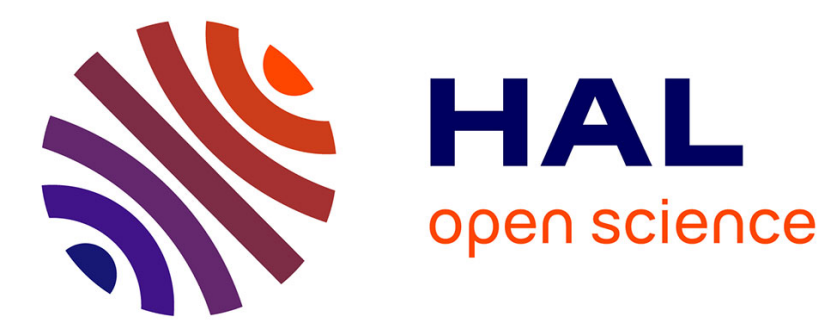

\title{
DEEP LEVEL DEFECTS IN SILICON AFTER BEAM PROCESSING IN THE SOLID PHASE REGIME
}

\author{
A. Chantre
}

\section{To cite this version:}

A. Chantre. DEEP LEVEL DEFECTS IN SILICON AFTER BEAM PROCESSING IN THE SOLID PHASE REGIME. Journal de Physique Colloques, 1983, 44 (C5), pp.C5-269-C5-280. 10.1051/jphyscol:1983542 . jpa-00223128

\section{HAL Id: jpa-00223128 https://hal.science/jpa-00223128}

Submitted on 1 Jan 1983

HAL is a multi-disciplinary open access archive for the deposit and dissemination of scientific research documents, whether they are published or not. The documents may come from teaching and research institutions in France or abroad, or from public or private research centers.
L'archive ouverte pluridisciplinaire HAL, est destinée au dépôt et à la diffusion de documents scientifiques de niveau recherche, publiés ou non, émanant des établissements d'enseignement et de recherche français ou étrangers, des laboratoires publics ou privés. 


\title{
DEEP LEVEL DEFECTS IN SILICON AFTER BEAM PROCESSING IN THE SOLID PHASE REGIME
}

\author{
A. Chantre \\ C.N.E.T. - Grenoble, B.P. 98, Chemin du Vieux Chêne, 38243 Meylan Cedex, \\ France
}

\begin{abstract}
Résumé - On passe en revue les récentes études de défauts dans le silicium traité par faisceau d'énergie en phase solide, en mettant l'accent sur la caractérisation électrique. On a abservé des défauts ponctuels en concentration de $10^{14}-1015 \mathrm{~cm}^{-3}$ dans les couches superficielles de plaquettes de silicium, implantées ou non, après recuit transitoire en phase solide. L'utilisation de la DLTS a permis de déterminer la nature microscopique de ces défauts, et de préciser les mécanismes mis en jeu dans leur introduction. Beaucoup d'informations pratiques concernant la production et la guérison de ces défauts ont ainsi été obtenues. On discutera les conséquences de ces travaux pour la réalisation des dispositifs et les applications aux études de défauts dans les semiconducteurs.
\end{abstract}

\begin{abstract}
Recent investigations of defects in cw beam processed silicon are reviewed, with emphasis on electrical characterization. Defect levels have been observed in concentrations of $10^{14}-1015 \mathrm{~cm}^{-3}$ in surface layers of silicon wafers, either ion-implanted or virgin, following beam processing in the solid phase regime. Deep Level Transient Spectroscopy (DLTS) has provided a unique insight into the microscopic nature of these defects, and the mechanisms of defect production. Practical informations concerning the conditions for defect introduction and removal have been obtained. Implications regarding device fabrication and thermally induced defects in silicon will be discussed.
\end{abstract}

\section{I - INTRODUCTION}

A wide variety of transient thermal processing techniques have been investigated in the past few years as alternatives to standard furnace heat-treatments. These processes are commonly classified into liquid phase and solid phase processes, according to whether or not a phase transformation occurs in the surface layers of the material. Recent research on liquid phase processes has been directed towards the obtention of single-crystal silicon films on insulating substrates for novel SOI technologies. Annealing of ion-implants and formation of refractory metal silicide films for future VLSI devices are better implemented through solid phase processes, which offer the distinct respective advantages to maintain initial dopant impurity profiles and single phase homogeneous silicide growth.

The potential impact of these emerging technologies has stimulated the need for comprehensive evaluation of the electronic properties of beam processed silicon. Defects have been given a particular attention in a number of laboratories. Defect annihilation under energy beam exposure has been demonstrated, while defect introduction was discovered. The results of these investigations will be reviewed in this paper, with emphasis on electrical characterization. Implications regarding device fabrication and defect studies in silicon will be discussed. It should be pointed out that only those studies related to solid phase processes will be addressed here, defects associated with the melt regime being the subject of a separate paper at this conference. 


\section{II - DEFECT REMOVAL DURING BEAM PROCESSING}

Both fundamental and practical considerations have stimulated research on beam induced defect annihilation. On the one hand, the high levels of charge excitation under cW laser or electron beam annealing offered the opportunity to seek modification of driving forces and enhancement of annealing kinetics. On the other hand, the presence of residual recombination centers in beam processed ion-implanted silicon had to be elucidated. The examples to follow summarize the current state of knowledge concerning these problems.

\section{1 - Ionization effects on defect annealing}

Search for jonization effects on defect annihilation during cw beam processing has been reported by STEIN et al /1/. Divacancies were produced in silicon by boron ion-implantation (100 keV $\left.-2 \times 10^{14} \mathrm{~B} / \mathrm{cm}^{2}\right)$ and monitored through a characteristic IR absorption band at $1.8 \mathrm{\mu m}$. Their annealing behavior under line-source electronbeam exposure (dwell times $5 \mu \mathrm{s}-2 \mathrm{~ms}$ ) was investigated and campared to the high temperature extrapolation of well characterized furnace annealing kinetics. The results of this study are iliustrated on Fig. 1, where the measured unannealed divacancy fractions have been plotted as a function of beam dwell time for two different beam power densities. The solid lines are the results of calculations assuming that the annealing mechanism is purely thermal. The agreement between measured and calculated data is indeed very good and was taken to be evidence that the thermal mechanism was adequate to describe divacancy annealing under electronbeam exposure. There is to date no indication that the high levels of electronic excitation reached during such beam processes may enhance point defect annihilation.

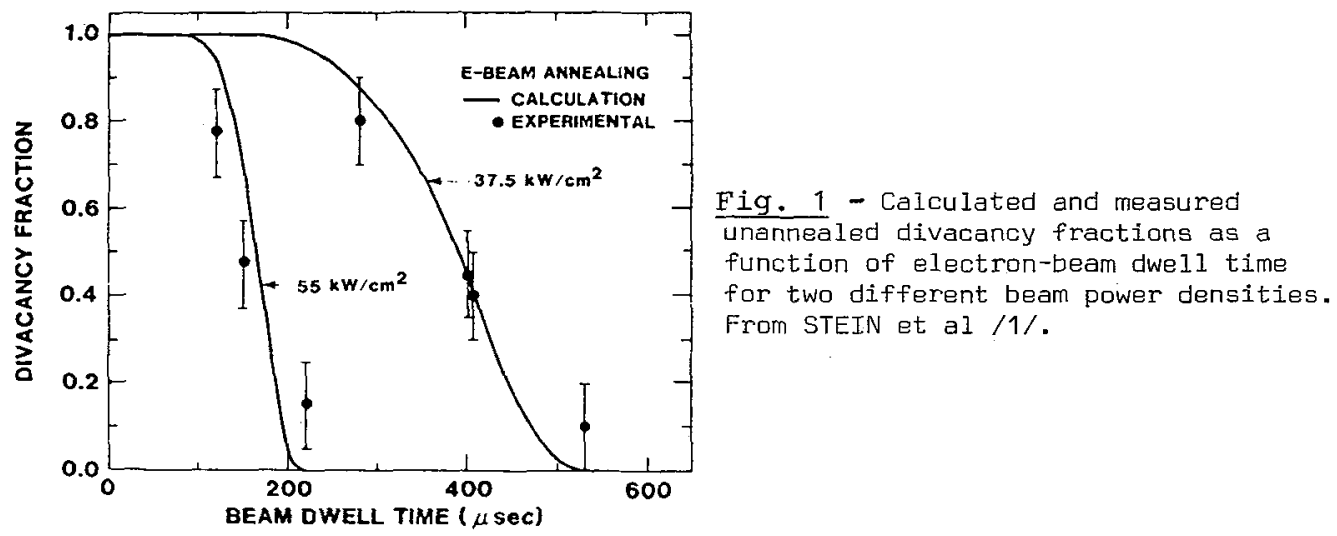

\section{2 - Implantation damage removal}

Whereas it has been soon demonstrated that ion-implanted layers could be annealed to a state of high structural perfection and electrical activity of the dopant using scanned cw lasers /2/ or electron-beams /3/, it has long been debated whether such processing techniques would remove defects buried beyond the implanted dopant distribution, i.e. in the semiconductor junction region. Residual electrically active point defects extending far (more than a micron) beneath the initially amoíphous layer were first reported by JOHNSON et al in beam processed As+-implanted $n^{*} / p$ junctions $/ 4 /$. These defects were tentatively associated with residual, buried implantation damage. Recent experimental findings to be described now favour an alternative explanation for the observed effects. Fig. 2a depicts a typical defect state spectrum of $\mathrm{As}^{+}$implanted p-type silicon samples following CW laser annealing, as reported by SHENG et al /5/. Two major hole traps are visible with energy levels at $E_{V}+0.10 \mathrm{eV}$ and $E_{V}+0.45 \mathrm{eV}$ (denoted a $H(0.10)$ and $H(0.45$ ) respectively). 
These authors claim to observe the same defect states in control samples which are thermally annealed at high temperature and then rapidly quenched into water $/ 6 /$. The resulting picture that the laser-induced thermal treatment itself rather than incomplete implantation damage removal may be responsible for these defects is further supported by independent measurements by CHANTRE et al /7/. Fig. 2b shows the capacitance transient spectrum reported for a bare p-type silicon sample, following cw laser irradiation in the solid phase regime. The same shallow H(0.10) level is observed to dominate in such initially undamaged sample. Evenmore, a second trap is observed in a ten times smaller concentration at EV +0.28 eV, very consistently with Fig. 2a. It should be emphasized that the deep H[0.45] state was also detected in this study $/ 7 /$; the DLTS feature does not appear on Fig. 2b because of the very peculiar properties of the corresponding defect, as will be discussed in Section III.1.
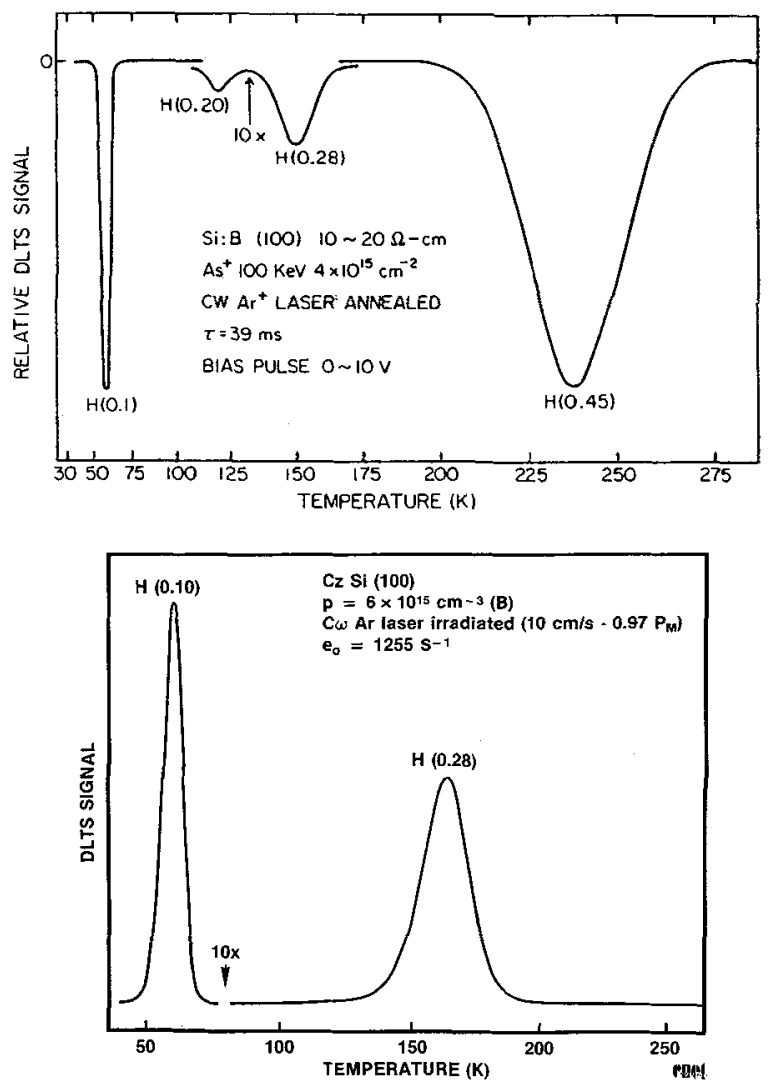

Fig. 2 - Typical capacitance transient spectrum of cw laser processed :

a - $\mathrm{As}^{+}$-implanted $\mathrm{p}^{-t y p e}$ silicon. From SHENG et al /5/. b - Bare p-type silicon. From CHANTRE et al $/ 7 /$.

Clearly, no buried implantation damage has to be invoked to account for the dominart residual defects in $\mathrm{CW}$ beam processed junctions. This conclusion may be simply understood in terms of reactions kinetics, as discussed by KIMERLING et al /8/and illustrated on Fig. 3. Here, the thermal annealing data for two major radiationinduced defects in silicon, the oxygen-vacency ( $V-0$ ) and phosphorous-vacancy (.P-V) associates, are shown along with the solid phase regrowth times for a $1000 \AA$ amorphous silicon layer. If the extrapolation of the low temperature data to the high beam-induced temperatures is valid, one readily sees why these defects wili be removed from the material. The defect recovery requires much less time than the epitaxial recrystallization of the amorphized layer, and will be complete under typical processing conditions. Similar arguments stand for the divacancy, one of the dominant defects in low-dose ion-implanted silicon /1, 9/. The results shown on Fig. 2 suggest that they indeed apply for even higher order defects. 


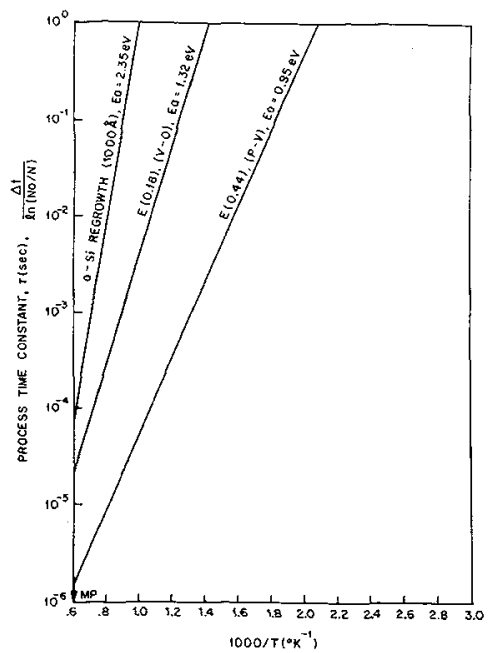

Fig. 3 - Recovery kinetics for some defects in silicon. From KIMERLING et al $/ 8 /$.

\section{III - DEFECT INTRODUCTION DURING BEAM PROCESSING}

Whereas laser induced melting and resolidification of single crystal silicon has soon been recognized to introduce electrically active point defects /8/, cW laser processing in the solid phase regime has long been believed to be free of similar effects /10/. Only recently have results such as Fig. 2b been reported, which unambiguously demonstrate that defect production mechanisms become activated far below the melting threshold /11/. The significance of beam-induced defects to device operation has stimulated intensive research in several laboratories, which has opened to a fair understanding of the phenomena. Defects have been identified on the microscopic scale; defect production mechanisms have been outlined. No equivalent knowledge for the melt regime has been gained so far. The most significant results of these investigations are presented in the following.

\section{1 - Defect properties}

Defect introduction by cw beam processing is best studied by observing changes induced in a bare, unimplanted material. Fig. 4 shows a typical DLTS spectrum of the defect states created by cw laser irradiation of virgin n-type silicon $/ 7 /$. The two major peaks represent electron traps, $E(0.22)$ and $E(0.45)$, which are present in concentrations of $\sim 1014 \mathrm{~cm}^{-3}$ within the experimental observation depth of $\sim 1$ micron. The spectrum is reproducibly observed in all phosphorus-doped substrates processed in the solid phase regime /11/. The same electronic defects have been reported by JOHNSON et al following scanned electron-beam irradiation /12/.

Several properties of these defects are noteworthy. The donor behaviour of E(0.22) has been established by studying the electron emission process with DLTS /7/. Fig. 5 shows the relationship between the apparent thermal activation energy for electron emission $\left(E_{a}\right)$ and the junction field in the test device $(F)$. The proportionality between $E_{a}$ and $F i / 2$ follows from a Poole-Frenkel field emission process $/ 13 /$. By this mechanism, the junction field reduces the binding energy between the ionized electron and the remaining positive ion (Coulomb well).

The charge state controlled stability of these laser-induced defects is demonstrated on Fig. 6 /7/. The change in charge state was performed by placing the defect energy levels either below (unbiased device) or above (reverse biased. device) the Fermi level during heat treatment. The most remarkable effect is found to occur at $E(0.45)$ : whereas only a minute fraction of the defects anneal during a 24 hours treatment at $80^{\circ} \mathrm{C}$ in the unbiased device, most when ionized have recovered after 
2 hours at this temperature. The effect is weaker for $E[0.22)$, but certainly underestimated in such a lightly doped material $\left(N_{0}=3 \times 10^{15} \mathrm{~cm}^{-3}\right)$, where the level is far from filled under zero bias conditions at $80^{\circ} \mathrm{C}$.
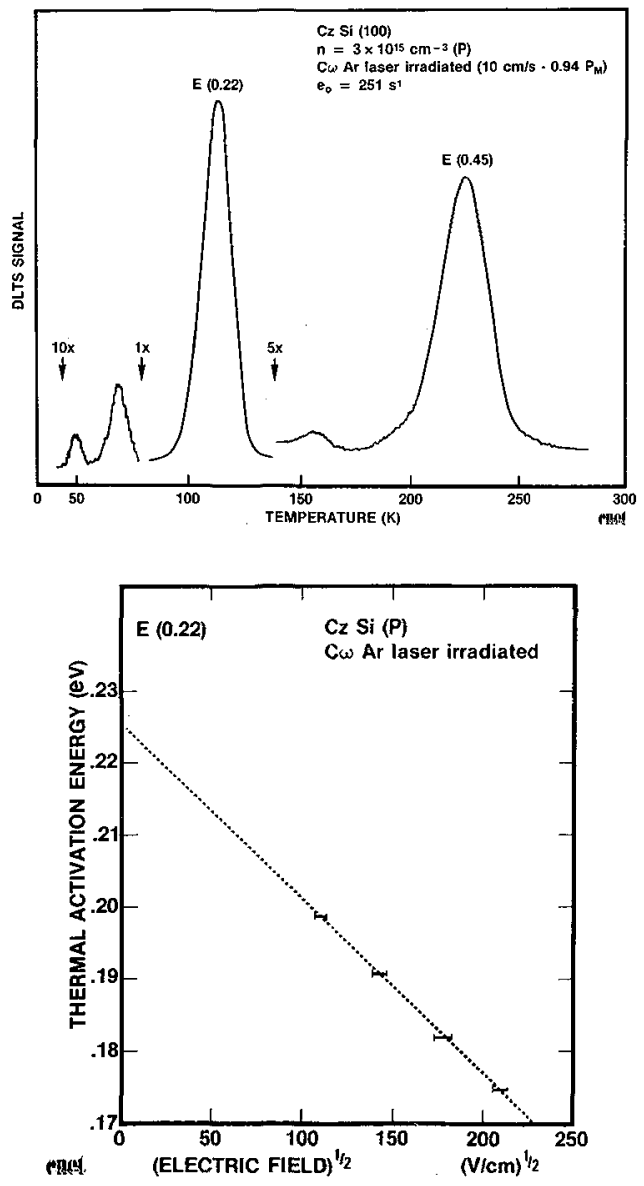

Fig. 4 - DLTS spectrum typical of cw laser irradiated P-doped silicon. From CHANTRE et al $/ 7 /$.
Fig. 5 - Electric field effect on electron emission from $E(0.22)$. From CHANTRE et al $/ 7 \%$.

Three major laser-induced hole traps have been observed in p-type silicon (Fig. 2). Defect reactions have been monitored during in situ low temperature thermal treatments /5, 7/. Fig. 7 illustrates the complementary behaviour of $H(0.10)$ and $H(0.45)$. Immediately after beam processing, $H(0.45)$ is dominant; however, it gradually decays at room temperature, while H(0.10) simultaneously increases; eventually, the deep level can no longer be detected (Fig. 2b). However, a subsequent low temperature $\left(100-200^{\circ} \mathrm{C}\right)$ thermal annealing restores the $H[0.45]$ level. Similar recovery has been observed under minority carrier injection $/ 5 /$. Accompanying reactions have been detected for $H(0.28)$; partial destruction of the defect level upon annealing at $110^{\circ} \mathrm{C}$, followed by a gradual recovery at room temperature, have been reported $/ 7 /$.

\section{2 - Defect identification}

The deep E(0.45) electron trap has been identified to the phosphorous-vacancy (P-V) associate (often referred to as E-center). The thermal signature of the level agrees with published data for this dominant radiation-induced defect $/ 11 /$. In agreement with this statement, the defect state has been shown to increase upon MeV electron irradiation /14/. Charge state effects have long been demonstrated to be 
operative for the annealing of the phosphorous-vacancy pair $/ 15 /$, consistently with the results shown on Fig. 6 . Finally, recent measurements (CHANTRE $A$. and KECHOUANE M., 1983, unpublished] have yielded a $0.95 \mathrm{eV}$ thermal activation energy for the disappearance of the ionized $E(0.45)$ defect, in close agreement with values reported for the neutral $\mathrm{P}-\mathrm{V}$ complex $/ 15 /$.

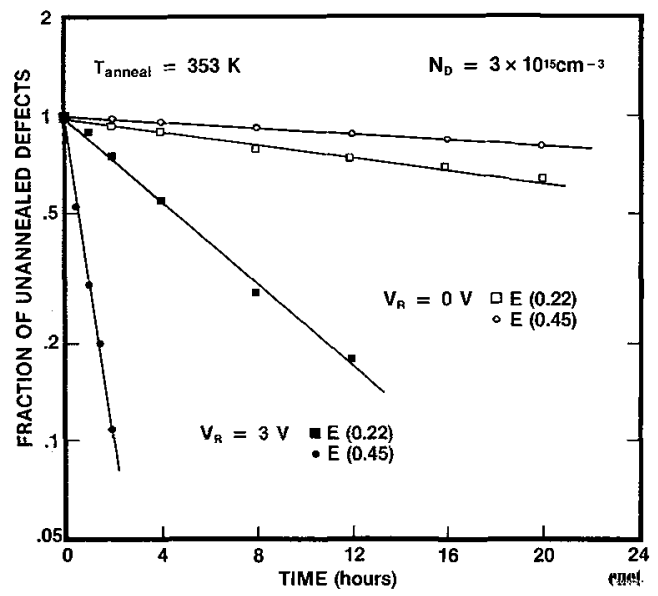

Fig. 6 - Charge state effects on the annealing kinetics of $E(0.22)$ and E(0.45). From CHANTRE et al /7/.

The data reported on Fig. 7 clearly show that the $H(0.45)$ and $H[0.10)$ hole traps are related : creation of one of the defects is accompanied by the annihilation of the other. These defect states arise from interstitial iron ( $\mathrm{Fe}_{\mathbf{i}}$ ) and iron-boron pairs $\left(\mathrm{Fe}_{i} \mathrm{~B}_{\mathrm{s}}\right\}$ respectively $/ 5 /$. Several workers have reported the occurrence of these two levels in quenched iron-contaminated silicon /16/, and a detailed study of electronically controlled reactions of iron and boron has been published recently $117 \%$ Interstitial iran present in the material immediately following beam pracessing introduces the deep donor state $H(0.45)$. The defect, which is positively charged in the unbiased device ( $p^{-t y p e}$ silicon), reacts with the negatively charged boron acceptor at room temperature to form the iron-boron pair H[0.10]. At elevated temperatures, the electrostatic, pair binding energy is countered by the available thermal energy, and the reaction is driven in the opposite way, dissociation.

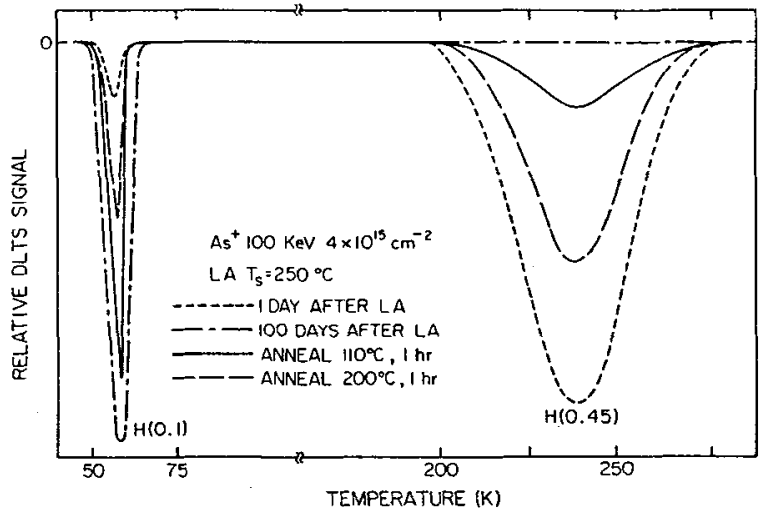

Fig. 7 - Transmutation between $\overline{H(0.45)}$ and $H(0.10)$ during low temperature thermal treatments. From SHENG et al $/ 5 /$.

Another transition metal impurity, chromium, either interstitial or paired with boron, accounts for the remaining two levels $/ 7 / . E(0.22)$ and $H(0.28)$ have been observed in chromium-doped silicon following rapid quenching /18/, and a detailed study of the system has been published recently /19/. Interstitial chromium (Cri) 
is produced in the material during ow laser irradiation, intraducing the E[0.22) donor state. This defect is positively charged in p-type silicon and pairs with boron acceptors to form $\mathrm{Cr}_{1} \mathrm{~B}_{\mathrm{S}}$ at $\mathrm{E}_{\mathrm{V}}+0.28 \mathrm{eV}$. The binding of the $\mathrm{Cr}_{i} \mathrm{~B}_{\mathrm{S}}$ pairs is rather weak and dissociation occurs at elevated temperatures, as experimentally observed. In n-type material, the pairing reaction involves a background acceptor (boron) concentration. This is demonstrated by recent (unpublished) measurements, which reveal enhanced annealing rates for E(0.22) in a counterdoped (boron) material. It should be pointed out that there is also some evidence that electric field enhanced motion of $\mathrm{Cr}_{i}{ }^{+}$is involved in the removal of E(0.22) in reverse-biased devices (CHANTRE A. and KECHOUANE M., 1983, unpublished).

\section{3 - Defect production mechanisms}

Several possible sources of defect introduction during laser processing have been discussed by KIMERLING et al /8/ : quench, substrate, ambient, crystal growth, stress gradients. The latter three do not seem to require consideration for the understanding of the solid phase regime. As shown below, the fast cooling rates alone reached in surface layers of $\mathrm{cw}$ beam processed silicon substrates indeed suffice to account for all the experimentally detected defects.

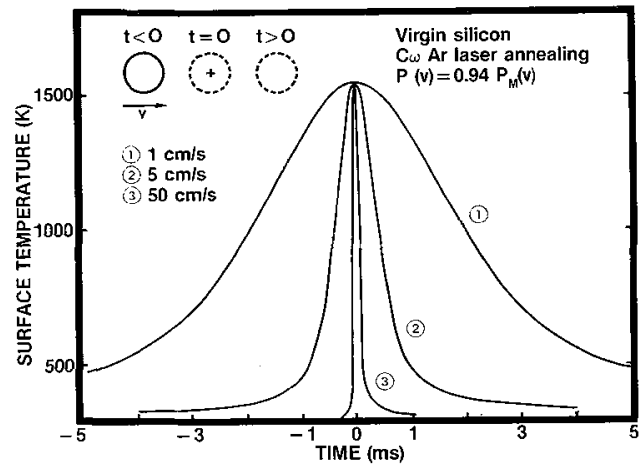

Fig. 8 - Typical transient surface temperature rise induced by cw annealing in the "point defects" regime calculated]. From CHANTRE et al $/ 14 /$.

Fig. 8 shows the (calculated) typical transient surface temperature rise induced by ow laser annealing in this "point defects" regime /14/. Temperatures as high as $1500 \mathrm{~K}$ are produced in the surface region of the material, which is subsequently cooled down to room temperature within a few milliseconds. Laser annealing is therefore also a thermal quenching situation, which normally produces the well known thermally induced defects in silicon, i.e. iron - and (to a lesser extent) chromium related defects $120 \%$. However, whereas these transition metal impurities are commonly ascribed to surface contamination during classical thermal quenching experiments, cw laser processing most certainly reveals the impurity content of the starting material /7\%. This conclusion is based on the following arguments :

(i) - The localized nature of beam-induced heat treatments eliminates sources of contamination associated with wafer handling,

(ii) - Wefers from different suppliers, chemicaliy prepared at the same time and beam processed under similar conditions, reveal markedly different defect concentrations (CHANTRE A. and KECHOUANE M., 1983, unpublished),

(iii) - Absolute concentrations of chromium provided by neutron activation analysis (NAA) and DLTS (through E(0.22) after beam processing) are consistent with each other (CHANTRE A. and JOURDAIN D., 1983, unpublished).

Iron and chromium are indeed two dominant metal impurities in silicon, especially in as-grown Czochralski material where they are present in the form of precipitates. These impurities dissolve on interstitial sites upon laser-induced heat treatments, where they remain frozen due to the fast associated cooling times. 
The characteristics of such thermal processes so closely approach the ideal conditions of the "perfect quench" experiment that they uniquely allow to detect what has been searched in vain so far in conventional quenching studies, i.e. trapping of intrinsic defects. The phosphorous-vacancy complexes discussed above indeed result from the interaction of thermal vacancies with dopant atoms /11/. The mechanism has been analyzed in some details and is illustrated on Fig. 9, which shows the depth profile of beam-induced $P-V$ centers for different laser scan velocities /14/. Care in processing was taken to avaid a change in laser-induced surface temperature between the different scans. In other words, Fig. 9 provides isothermal introduction data for $P-V$ centers. The results point out a diffusion mechanism from the surface of the samples during the treatment. Briefly, the localized temperature rise produced in the material activates vacancy generation processes, which are indeed most efficient in the very top layers. The surface then serves as a source for vacancy diffusion into the substrate, where interaction with phosphorous atoms takes place. Thermal equilibrium can be maintained during the whole transient thermaI treatment in these upper layers, hence the experimentally observed surface depletion of defects. Vacancy trapped deeper in the material cannot escape during the ultrashort cooling periods, to be detected later through the $E(0.45)$ electron trap.

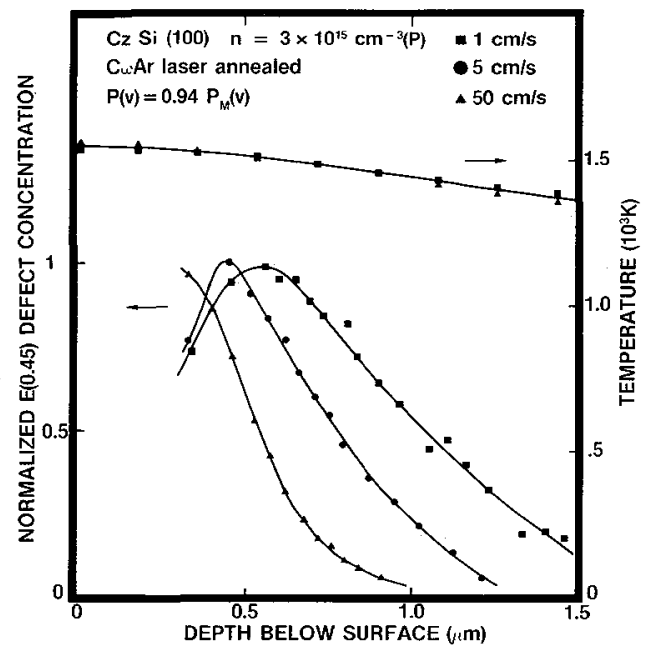

Fig. 9 - Depth profiles of P-V centers generated by cw laser irradiation, with laser scan speed as a parameter. From CHANTRE et al $/ 14 /$.

\section{IV - IMPLICATIONS : DEVICE PROCESSING AND DEFECT ${ }^{-}$STUDIES}

The laser-induced defect introduction. problem discussed above has introduced two fruitful areas for experimental research : one, investigation of the role these defects play in beam processed devices and the conditions of their removal; two, application of energy beams to defect studies in semiconductors. Recent progress on these topics are briefly surveyed in the remaining of this paper.

\section{1 - Device processing}

As discussed in Section II.2, the beam induced defects are detected in the space charge layers of cw laser annealed ion-implanted junctions. These defects would be produced as well in active regions of devices, when using for example laser-assisted silicide growth for Schottky contacts or gates in MOS transistors. The critical effects of these defects on device performance have been demonstrated by SHENG et al /6/. The results of this study are illustrated on Fig. 10, which displays the defect $\left(\mathrm{Fe}_{i}\right.$ ) concentration measured by DLTS in $n^{+} / p$ junctions as a function of annealing beam power, together with the charge-collection efficiency measured by EBIC (Electron-Beam-Induced Current) on the same diodes. Clearly, the minoritycarrier collection efficiency decreases as the defect concentration increases. 
Similar observations have been independently reported by CHANTRE et al /11/. GONCHOND et al /21/also provided evidence that beam induced defects are responsible for lateral dark lines in the EBIC pattern of single laser scans. All the above results demonstrate that these defects serve as efficient carrier generation and recombination centers in beam processed junction devices. Reduction of defect concentrations is therefore necessary to apply these techniques to device manufacture. Subsequent moderate temperature annealing steps, or optimized processing conditions, may be considered.

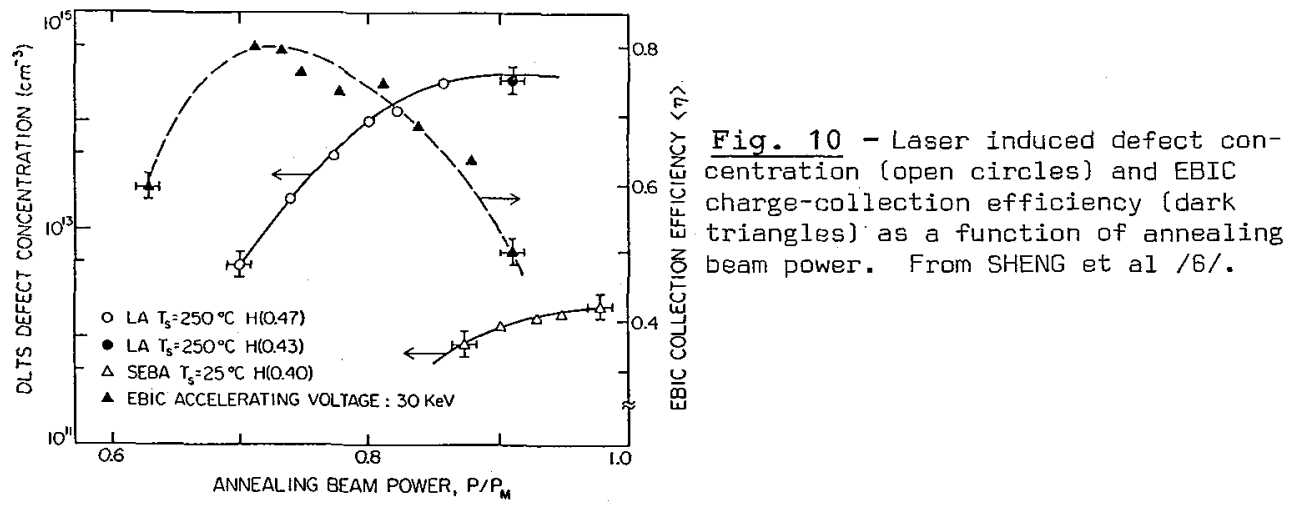

As shown in Section III.2, all dominant laser induced defects are common defects in silicon; their furnace annealing behaviour is properly documented as well. Phosphorous-vacancy centers anneal out at $\sim 150^{\circ} \mathrm{C}$ in the negative charge state lunbiased devicej /15/. The annealing mechanism is believed to be one of migration to sinks and annihilation; no electrically active defect seem to result from their disappearance /22/. Iron - and chromium - related defects also respond to low temperature thermal treatments. As discussed above, these reactions first involve dissociation of interstitial metal-dopant acceptor pairs, which form during sample storage at room temperature. Impurity precipitation then occurs at somewhat higher temperatures $\left(100^{\circ} \mathrm{C}-200^{\circ} \mathrm{C}\right.$ for iron, above $200^{\circ} \mathrm{C}$ for chromium) $/ 16$, 19/. It should be pointed out however that such precipitated impurities may still deteriorate the reverse current-voltage characteristics of devices $/ 18 /$.

Substrate heating, which is often required to avoid dislocation generation during cw beam processing, should reduce point defect production as well. Metal-related states however are still present following $\mathrm{cw}$. laser processing with $T_{S}=250^{\circ} \mathrm{C}$ ( $\mathrm{Fig}$. $2 \mathrm{a}$ ) ; increasing the substrate temperature to $350^{\circ} \mathrm{C}$ significantly lowers the concentration of iron-related defects /5/. Processed samples should be kept heated long enough for impurity precipitation to be complete.

Beam processing conditions can finally be optimized to limit defect production in active regions of junction devices. This is demonstrated in a recent analysis of the influence of scan speed on defect generation during $\mathrm{CW}$ laser irradiation of virgin silicon material /23/. The results of this investigation are illustrated on Fig. 11, which shows the averaged concentrations of beam-induced $E[0.22]$ and $E[0.45]$ electron traps, as a function of laser scan velocity. It can be seen that the defect density is reduced by almost two orders of magnitude as the scan speed is increased from 1 to $100 \mathrm{~cm} / \mathrm{s}$. Again, processing parameters in these experiments were chosen in such a manner that no change in temperature distribution in the sample accompanied a change in scan speed. The data shown on Fig. 11 reflect the reduced filling of the observation depth $[\sim 2 \mu \mathrm{m})$ with defects, as the duration. of the laser induced heat treatment shortens. As suggested by Fig. 12 for E $(0.22)$ and Fig. 9 for $E(0.45)$, with current cW laser annealing equipments, no processing conditions will be found, that avoid defect generation in junction space charge layers. Shorter dwell. times $[\sim 10 \mu \mathrm{s}]$, as attainable with scanned electron-beams owing to their smaller spot sizes, would retain defects in the implanted layer 
thickness, where they no longer serve as efficient charge generation and recombination centers. Much more promise however is offered by recently developed rapid thermal annealing techniques using incoherent light sources or graphite strip-heaters. As predicted by Fig. 12, the characteristic heating cycles of $\sim 1$ sec involved in these techniques will indeed leave defects only far below the active layers of the device. Preliminary DLTS results carried out on ion-implanted junctions following halogen lamp annealing are consistent with these predictions /24/.
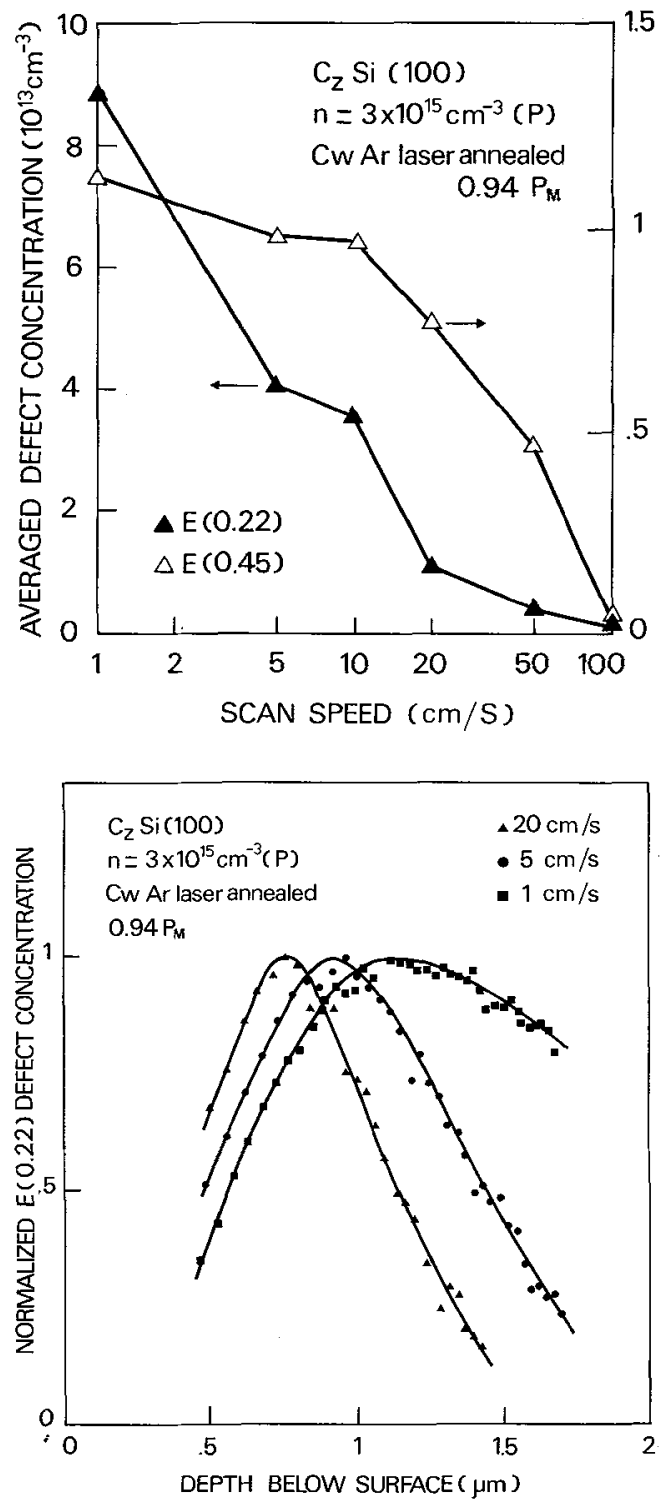

Fig. 11 - Scan speed dependence of averaged laser induced defect concentrations. From CHANTRE et al $/ 23 /$.
Fig. 12 - Influence of laser scan speed on the spatial depth profile of the E[0.22) ievel. From CHANTRE et al $/ 23 /$.

\section{2 - Defect studies}

Energy-beam irradiation in the solid phase regime is emerging as a new powerful technique for defect studies in semiconductors. Informations brought about by this 
technique are complementary to those provided by MeV electron (or related) irradiations. As demonstrated in Section III, beam processing offers the unique opportunity to probe transition metal impurities which are hidden in precipitates in most silicon substrates ; such impurities are indeed not activated during classical electron irradiations. With subsequent DLTS measurements, concentrations as low as $\sim 10^{10} \mathrm{~cm}^{-3}$ (for a typical doping level of $\sim 10^{15} \mathrm{~cm}^{-3}$ ) may be detected, which is beyond the sensitivity of neutron activation analysis. Several applications may be envisioned, such as control of the efficiency of gettering processes, or determination of metal impurity content in thin silicon films.

As discussed in Section III.3, cw beam processing also shows promise for the understanding of thermally induced defects in semiconductors. The accessible high temperatures and fast cooling rates have allowed the first identification of an impurity-intrinsic defect complex in quenched silicon (the phosphorous-vacancy pair). This observation also constitutes the first direct experimental support to the involvement of E-centers in phosphorous diffusion in silicon $/ 25 /$. A careful theoretical treatment of P-V isothermal introduction data (such as given on Fig. 9 ), should provide quantitative informations on the properties of vacancies and E-centers at high temperatures. Similar data should be obtained on self-interstitials as well, in so far as they are believed to be present in large concentrations at high temperatures $/ 26 \%$. Search for weel known interstitial-related defects (carbon - and boron - related) in cW laser irradiated silicon has been so far unsuccessful (CHANTRE A., 1983, unpublished).

\section{$\mathrm{V}$ - SUMMARY}

Defect studies on laser processed semiconductors are still at an early stage. In silicon however, much experimental work has been carried out in the last years, and a good degree of understanding has been reached, particularly for the solid phase regime. CW laser processing has proven a versatile tool for basic studies. Defect removal during beam annealing has been demonstrated. Defect introduction has been evidenced and extensively studied. New processing techniques have emerged, which avoid defect production in active regions of devices. Cw laser irradiation shows more promise as a new technique for defect studies in semiconductors.

The author is indebted to Drs STEIN H. J., MERZ J. L. and KIMERLING L. C. who responded to requests for glossy photographs. The figure ceptions are referenced to the individual contributors.

\section{REFERENCES}

/1/ STEIN H. J., KNAPP J. A. and PEERCY P. 5., Laser and Electron-Beam Interactions with Solids 1981, edited by APPLETON B. R. and CELLER G. K. (North Holland, Amsterdam, 1982) p. 319.

12/ GAT A., GibBONS J. F., MAgeE T. J., PENG J., DELINE V., WILliams P. and EVANS C. A. Jr, Appl. Phys. Lett. 32, 276 (1978).

/3/ REgOLINI J. L., GIBBDNS J. F., SIGMON T. W., PEASE R. F. W., MAGEE T. J. and PENG J., Appl. Phys. Lett. 34, 410 (1979).

/4/ JOHNSON N. M., BARTELINK D. J., MOYER M. D., GIBBONS J. F., LIETOILA A., RATNAKUMAR K. N. and REGOLINI J. L., Laser and Electron-Beam Processing of Materials 1979, edited by WHITE C. W. and PEERCY P. S. (Academic Press, New York, 1980] p. 423.

/5/ SHENG N. H. and MERZ J. L., Laser and Electron-Beam Interactions with Solids 1981, edited by APPLETON B. R. and CELLER G. K. (North Holland, Amsterdam, 1982) P. 313.

/6/ SHENG N. H., MIZUTA M. and MERZ J. L., Appl. Phys. Lett. 40, 68 (1982).

17/ CHANTRE A., KECHOUANE M. and BOIS D., Defects in Semiconductors (Materials Research Society, Boston, 1982). To be published.

/8/ KIMERLING L. C. and BENTON J. L., Laser and Electron-Beam Processing of Materials 1979, edited by WHITE C. W. and PEERCY P. S. (Academic Press, New York, 1980] p. 385.

19/ WANG K. L., Appl. Phys. Lett. 36, 48 (1980). 
/10/ ROZGonYI G. A., in Festkörperprobleme (Advances in Solid State Physics), Vol. XX, edited by TREUSCH J. (Braunschweig, 1980) p. 229.

111/ CHANTRE A., KECHOUANE M. and BOIS D., Laser and Electron-Beam Interactions with Solids 1981, edited by APPLETON B. R. and CELLER G. K. (North Holland, Amsterdam, 1982$\}$ p. 325.

/12/ JOHNSON N. M., REGOLINI J. L., BARTELINK D. J., GIBBONS J. F. and RATNAKLMAR K. N., Appl. Phys. Lett. 36, 425 (1980).

/13/ FRENKEL J., PhYS. Rev. 54, 647 (1938).

/14/ CHANTRE A., KECHOUANE M. and BOIS D., Defects in Semiconductors 1982, edited by AMMERLAAN C. A. J. (North Holland, Amsterdam, 1983); Physica 1168, 547 (1983).

/15/ KIMERLING L. C., DE ANGELIS H. M. and DIEBold J. W., Solid State Commun. 16, $171(1975)$.

/16/ GRAFF K. and PIEPER H., J. Electrochem. Soc. 128, 669 (1981), and references herein.

/17/ KIMERLING L. C. and BENTON J. L., Defects in Semiconductors 1982, edited by AMMERLAAN C. A. J. (North Holland, Amsterdam, 1983); Physica 116B, 297 (1983).

/18/ GRAFF K. and PIEPER H., Semiconductor Silicon 1981, edited by HUFF H. R. and KRIEGLER R. J. (The Electrochemieal Society, N. J., 1981) p. 331.

119/ CONZELIMANN H., GRAFF K. and WEBER E. R., Appl. Phys. A30, 169 (1983).

$120 \%$ LEE Y. H., KLEINHENZ R. L. and CORBETT J. W. , Defects and Radiation Effects in Semiconductors 1978 ; Inst. Phys. Conf. Ser. 46, 521 (1979).

/21/ GONCHOND J. P., ROZGONYT G. A. and BOIS D., Laser and Electron-Beam Interactions with Solids 1981 , edited by APPLETON B. R. and CELLER G. K. (North Holland, Amsterdam; 1982) p. 189.

$122 /$ KIMERLING L. C., Radiation Effects in Semiconductors 1976 ; Inst. Phys. Conf. Ser. 31, 221 (1977).

/23/ CHANTRE A., KeCHOUANE M., AUVERT G. and BOIS D., Appl. Phys. Lett. 1983, to be published.

124/ HAOND M. and VU D. P., Electron. Lett. 18, 727 (1982).

/25/ FAIR.R. B. and TSAI J. C. C., J. Electrochem. Soc. 124, 1107 (1977).

/26/ GÖSELE U. and TAN T. Y., Defects in Semiconductors TMaterials Research Society, Boston, 1982], to be published. 